\title{
Characterizing right ventricular shape variations via subject adapted voxel-based morphometry: application to CMR of Tetralogy of Fallot
}

\author{
Dong Hye Ye*, Christos Davatzikos and Harold Litt
}

Address: University of Pennsylvania, Philadelphia, PA, USA

* Corresponding author

from 13th Annual SCMR Scientific Sessions

Phoenix, AZ, USA. 21-24 January 2010

Published: 21 January 2010

Journal of Cardiovascular Magnetic Resonance 20 I0, I2(Suppl I):P237 doi:I0.I I86/I532-429X-I2-SI-P237

This abstract is available from: http://jcmr-online.com/content/I2/SI/P237

(c) 2010 Ye et al; licensee BioMed Central Ltd.

\section{Introduction}

Tetralogy of Fallot (ToF) is the most common complex congenital heart defect, and involves abnormalities in right ventricle (RV). Voxel-based morphometry (VBM) is a widely used method for characterization of morphological variations between normal and pathologic states. VBM can facilitate statistical analysis across population groups of regional heart shape, registering each heart to a common template (or atlas) so that structures have similar shape, size and orientation among subjects. Then, by analyzing the transformation map, one can investigate subtle structural or functional changes. In conventional VBM, the template and transformation parameters are chosen empirically. The Auckland cardiac atlas can be used as a standard template, and a common transformation parameter is assigned to all subjects. However, the use of an arbitrary template introduces bias and the best set of transformation parameters needs to be optimized for each subject. We have developed a method for determining optimal template and transformation parameters for individual subjects by solving a global optimization problem that improves the statistical power to detect group differences between normal and pathological anatomy.

\section{Purpose}

To apply a new method for determining the optimal template and transformation parameters for each subject in VBM to the characterization of RV shape variations in ToF.

\section{Methods}

Short axis TrueFISP images of the heart obtained at enddiastole in 12 normal volunteers and 12 ToF patients were evaluated. First, a linear transformation was applied to minimize variability in orientation and overall size of the hearts. A representative template that minimizes the sum of shape distance from each subject was selected. Then, all subjects were registered onto the template through a diffeomorphic shape transformation. In order to identify regional volumetric changes which reflect ventricular shape changes, we calculated the Jacobian determinant from the shape transformation. We then estimated the

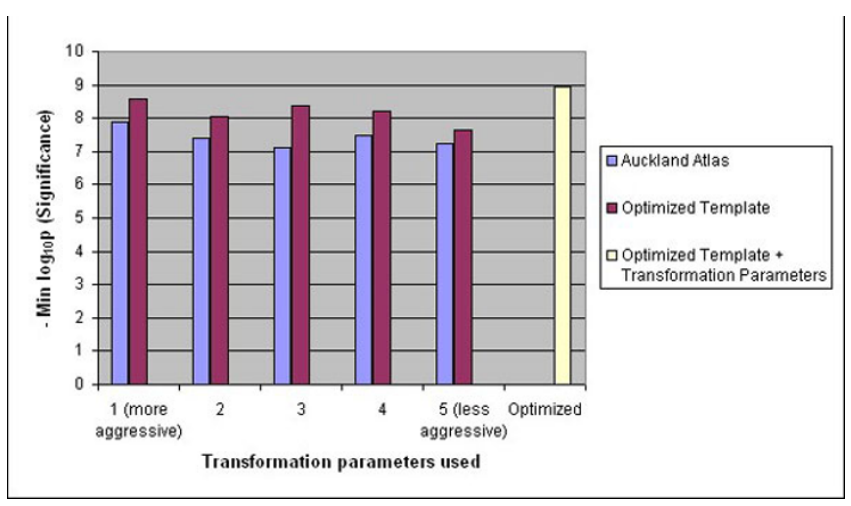

Figure I

Statistical significiant of shape changed in ToF with and without optimized parameters and template. 


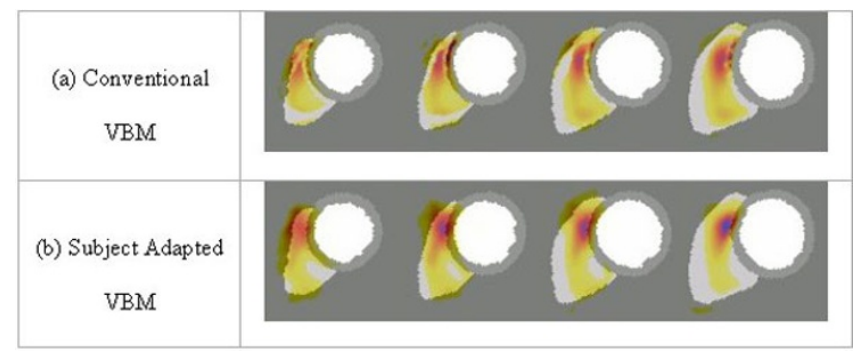

Figure 2

Regions of statistically significant shape changes in ToF.

best set of transformation parameters for each subject using an advanced optimization formulation.

\section{Results}

Use of an optimized template resulted in increased statistical significance of the differences between the ToF hearts and the template for all chosen parameters; addition of optimized parameters resulted in further improvement (Figure 1). Regions of statistically significant shape change from normal were more accurately localized to the RVOT using subject adapted VBM compared to conventional VBM (Figure 2).

\section{Conclusion}

Optimization of a template and transformation parameters resulted in improvements in quantifying and localizing RV shape changes in ToF over conventional VBM. Future work will include analysis of other pathology such as ARVD.
Publish with Biomed Central and every scientist can read your work free of charge

"BioMed Central will be the most significant development for disseminating the results of biomedical research in our lifetime. " Sir Paul Nurse, Cancer Research UK

Your research papers will be:

- available free of charge to the entire biomedical community

- peer reviewed and published immediately upon acceptance

- cited in PubMed and archived on PubMed Central

- yours - you keep the copyright

Submit your manuscript here:

http://www.biomedcentral.com/info/publishing_adv.asp 